\title{
Embedded Based Soil Electrical Conductivity Measurement System
}

\author{
B.SalehaBegum ${ }^{1}$, B.AshrafAhamed ${ }^{2}$, Prof.A.Suresh Kumar ${ }^{3}$, \\ Prof.B.RamaMurthy ${ }^{4}$ Dr. P.Thimmaiah ${ }^{5}$, Dr. K.K.Azam Khan ${ }^{6}$ \\ 1. Research Scholar, Department of Instrumentation, S.V.University, Thirupathi, A.P, India. \\ 2. Research Scholar, Department of Electronics, Sri Krishnadevaraya University, Anantapur, A.P, India. \\ 3. Department of USIC, S.V.University, Thirupati, A.P, India. \\ 4. Department of USIC, S.K.Uiniversity, Anantapur, A.P, India. \\ 5. Department of Electronics, S.K.University, Anantapur, A.P, India. \\ 6. R\&D Division, EchoMRI Pte Ltd, Singapore.
}

\begin{abstract}
Electrical Conductivity measurements are often used to measure the amount of soluble salts in the soil. It is most common measure of soil salinity and is indicative of the ability of an aqueous solution to carry an electrical current.

By Agricultural standards, soils with an Electrical Conductivity greater than $4 d s / m$ are considered for saline. In actually salt-sensitive plants may be affected by conductivities less than $4 \mathrm{ds} / \mathrm{m}$ and salt tolerant species may be impacted by concentrations of up to twice this maximum agricultural tolerant limit. Hence in the present an attempt is made to implement and embedded based soil conductivity meter.
\end{abstract}

Keywords: Agriculture, Analyzer, Conductivity, Instrumentation, Salinity, Soil.

\section{Introduction}

Electrical Conductivity/Specific Conductance is the reciprocal quantity and material's ability to conduct an electric current. It is commonly represented by the Greek letter . Its S.I Units Siemens per meter.

Where $P$ is Electrical Resistivity in ohm meter.

$$
\rho=1 / p
$$

The electrical conductivity of soils varies depending on the amount of moisture held by soil particles. Sands have a low conductivity. Silts have a medium conductivity and clays have high conductivity. Consequently soil electrical conductivity correlates strongly to soil partial size and texture. A measurement correlates with soil properties that affect crop productivity including soil texture. Caution exchange capacity. Drainage conditions organic matter level salinity and subsoil characteristics.

\section{Theory}

The conductivity of an electrolyte is a measure of the ability of the solution to carry electricity. The current through the solution takes place through the movement of electrically charged particles called ions. When a potential difference is applied to electrode immersed in the solution ions are almost instantaneously accelerated towards the electrode. Since the conductance of a solution of electrolyte is related to the concentration of electrolyte, analytical applications of conductance are possible. The electrical conductivity measurement system in the present study is shown in fig.

\section{Conductivity Cell}

The conductivity cell comprises two electrodes which are two parallel sheets of platinum fixed in position by scaling the connecting tubes into the sides of the measuring cell. In order to reduce the polarization effects which produce a large cell capacitance, the effective area of the electrode is greatly increased by coating the electrode with platinum black.

The reciprocal of the resistance $R$ of the electrolytic solution $(1 / R)$ is called the conductance. It is expressed in reciprocal ohms or mhos. The resistance of a solution depends upon the length 1 , area a and the intrinsic properties of the solution. It can be expressed as: $\mathbf{R}=\boldsymbol{\rho}(\mathbf{l} / \mathbf{a})$

Where $\rho$ is known as specific resistance. The conductance of the cell is given by

$$
1 / R=1 / \rho(a / l)=\sigma(a / l)
$$

The constant $\sigma$ is called the specific conductance of an electrolyte.

$$
\sigma=1 / R(1 / a) \text { in } \Omega^{-1 / C m}
$$


The cell constant can be determined by measuring R for a solution of known specific conductance. Solutions of potassium chloride of known concentrations are invariably employed for this purpose.

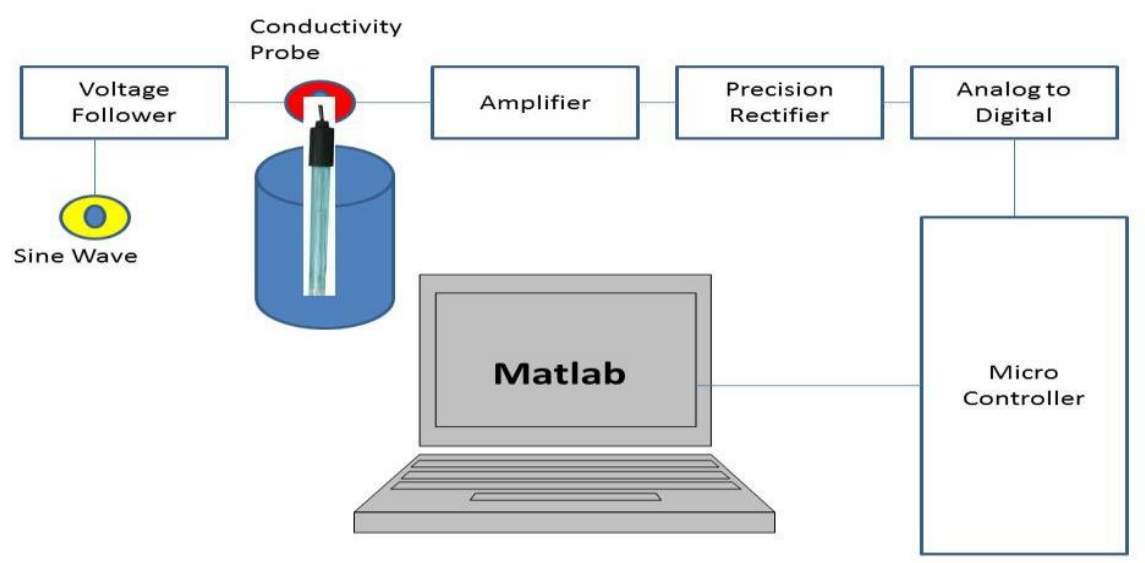

Fig 1: Conductivity Measurement

\section{Details of the circuit:}

Sine wave input $-400 \mathrm{mV}, 1 \mathrm{KHz}$ generated using Function generator chip 8038

$\mathrm{U} 1$ - U4 : OP07

$\mathrm{R} 1=1 \mathrm{~K} \mathrm{Ohm}$

$\mathrm{R} 2$ to $\mathrm{R} 7=10 \mathrm{~K} \mathrm{Ohm}$

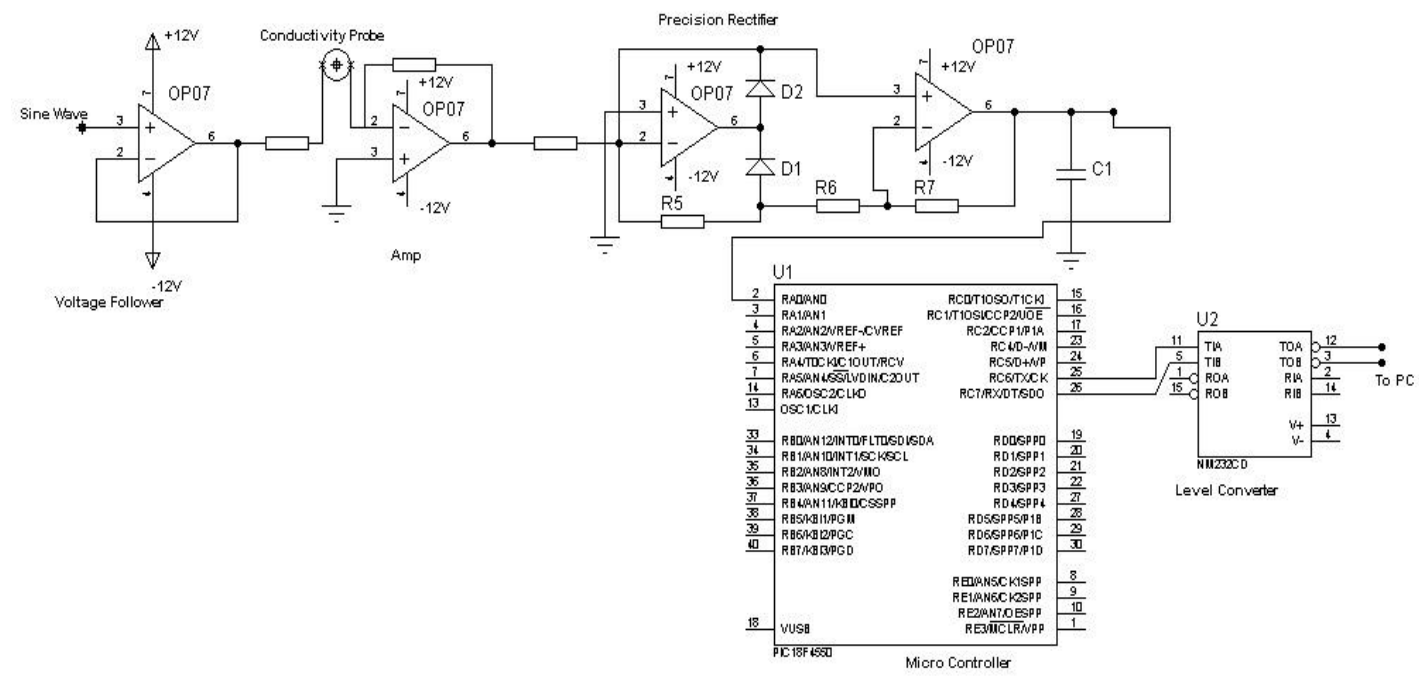

\section{Working of the circuit:}

The individual blocks of the embedded based system for the measurement of electrical conductivity is designed and constructed. The details are shown in Figure 1: The necessary software is developed MATLAB which runs in PC. The software for analog to digital conversion and serial communication is written in $\mathrm{C}$ language, which is flashed into the PIC microcontroller of Pinguino kit. Details of Pinguino kit can be found at www.pinguino.cc. The microcontroller kit is connected to the PC via USB interface. The measurements are stored in a file for further usage.

\section{Calibration procedure:}

Before using the system, the electrode must be calibrated by measuring a series of known standard solutions, made by serial dilution of the 1M KCL standard solution. In the present study, the system is calibrated 
at three concentrations of standard KCL solution- $1 \mathrm{M}, 0.1 \mathrm{M}$ and $0.01 \mathrm{M}$. The standard solutions were prepared by the dilution method.

In the calibration process, the slope of the conductivity electrode is calculated. Slope is defined as the observed change in potential $(\mathrm{mV})$ with a decade change in concentration. Obtaining the slope ensures good operation of the electrode. Slope measurement involves the following steps. The slope is computed by measuring the voltages at $0.1 \mathrm{M}$ and $0.01 \mathrm{M}$ standard solutions. The calibration values are stored in MATLAB code for the measurement. The conductivity of a solution is highly temperature dependent. Therefore, it is to be temperature compensated, or calibrate the instrument at the same temperature as the solution being measured. Unlike metals, the conductivity of common electrolytes typically increases with increasing temperature.

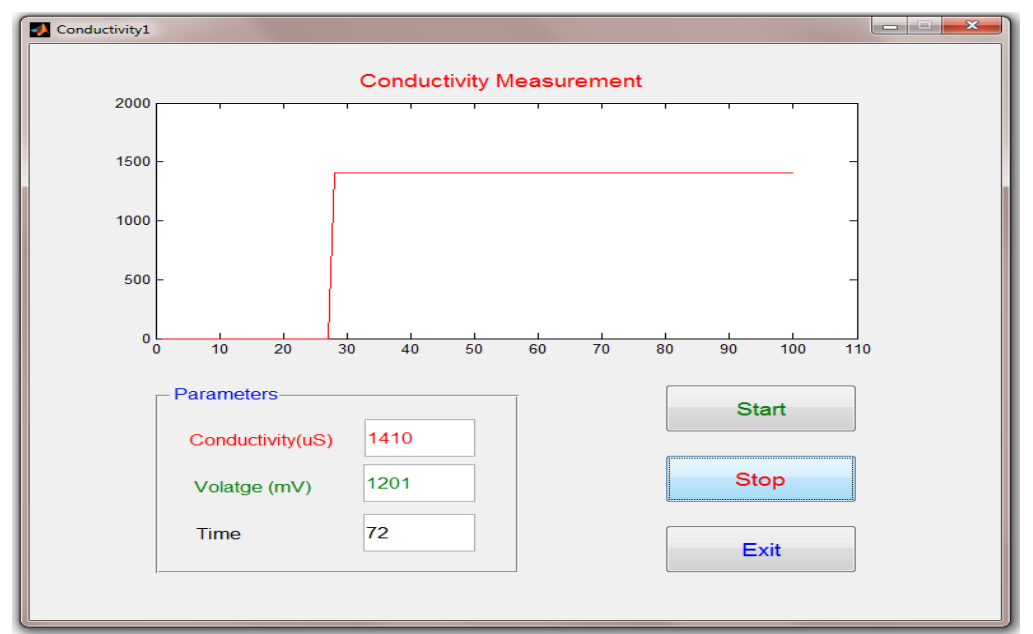

Fig 2. Screen Shot of the measurement GUI

Known solution Electrical Conductivity

\section{Results}

\begin{tabular}{|l|l|l|}
\hline KCl Concentrations & Electrical Conductivity(uS) & Measured Conductivity(uS) \\
\hline $1 \mathrm{M}$ & 111342 & 111341 \\
\hline $0.1 \mathrm{M}$ & 12854 & 12856 \\
\hline $0.01 \mathrm{M}$ & 1408 & 1410 \\
\hline $0.001 \mathrm{M}$ & 146.93 & 145.87 \\
\hline
\end{tabular}

\section{Unknown Solution Electrical Conductivity}

\begin{tabular}{|l|l|l|}
\hline Village of the soil sample & Electrical Conductivity(uS) & Measured Conductivity(uS) \\
\hline Rapthadu & 863 & 857 \\
\hline Tagarakunta & 2070 & 2067 \\
\hline Sanapa & 1690 & 1688 \\
\hline
\end{tabular}

\section{Conclusion} ELECTRODE.

By using "Instrumentation based soil analyzer", we measure Electric Conductivity at respective

This system is connected to PIC Microcontroller, which has special feature of built in Analog to Digital converter. This device is more economical, reliable, and portable. Using this instrument, farmers can measure conductivitymanually or in real time with regular intervals. Real time monitoring us important, where the electrode is fitted in the drip irrigation system, where we can monitor the conductivity of the fluids pumped in the drip irrigation channels. Using this system farmer can evaluate the soil nutrients present in the soil and lack of percentage of nutrients to be added for a specific crop by using predefined data provided. A farmer can have the suggestions from soil analysts or agricultural scientists through Internet, so that he can improve the crop yields in an efficient manner. 


\section{References}

[1]. Geophysical Survey Systems athttp://www.geophysical.com.

[2]. Doolittle, J.A., K.A. Sudduth, N.R. Kitchen and S.J. Indorante. 1994. Estimating depths to claypans using electromagnetic induction methods. J. Soil and Water Cons. 49:572-575.

[3]. Geonics Limited. 1980. Electrical conductivity of soils and rocks. Technical Note 5. http://www.geonics.com/lit.html

[4]. Halvorson, A.D. and J.D. Rhoades. 1974. Assessing soil salinity and identifying potential s aline seep areas with field soil resistance measurements. Soil Sci. Soc. Amer. Proc. 38:576 -581.

[5]. Jaynes, D.B. 1996. Improved soil mapping using electromagnetic induction surveys. Precision

[6]. Agriculture, Proceedings of the $3^{\text {rd }}$ International Conference, Ed. P.C. Robert, R.H. Rust and W.E.Larson. p. 169-179.

[7]. Jaynes, D.B., J.M. Novak, T.B. Moorman and C.A. Cambardella. 1994. Estimating herbicide partition coefficients from electromagnetic induction measurements. J. Environ. Qual. 24:26-41.

[8]. ArchanaMangla\&Anjansil, indian J Pure \& Apply Phys, 39 (2001) 267.

[9]. Sheehan W F, Physical Chemistry (Prentice Hall of India), 1966,412.

[10]. Takagishi E, IEEE Trans Instrum, Meas, 29 (1980) 131. 